\title{
E-BRIEF
}

\author{
September 4, 2014
}

\section{ECONOMIC GROWTH AND INNOVATION}

\section{Rethinking Ontario's Electricity System with Consumers in Mind}

\author{
by \\ Michael Wyman
}

- Ontario electricity consumers stand to benefit from lower electricity prices and less risk if the province moves to a capacity market for obtaining generation.

- Relative to Ontario Power Authority's 20-year power purchase agreements, a capacity market could better match demand for new power capacity with how much and what type of supply materializes, resulting in less excess capacity and lower prices for consumers.

- Such a market would also provide a more economical mix of fuels and supply than centralized procurement. Plus, market mechanisms can be supplemented by any government-established environmental regulations and emission controls.

- Finally, a capacity market would help allocate project development risk to the most logical risk bearer: the project developer.

Ontario's power system is entering another period of transition. After a decade of relying on the Ontario Power Authority (OPA) to procure capacity, rather than relying on market-oriented options, rising power costs have shown the limitations of this approach (Goulding 2013a).

The Independent Electricity System Operator (IESO), the market operator, has begun exploring a capacity market for Ontario. In a capacity market, in its purest form, generators receive payments for being available to produce energy if needed at some point in the future, in addition to payments for actual production at a given price, in a given hour (Oren 2000).

The author would like to thank all who provided feedback on this paper. All errors are the author's responsibility. 
Relying on a capacity market for contracting generation, rather than a centrally managed process, likely would result in lower electricity prices and less risk for Ontario electricity consumers. If the Ontario government committed itself to a capacity market, the result would be more transparency, helping to avoid many of the behind-closed-door contract negotiations common in Ontario.

\section{The Politicization of Wholesale Generation Purchases}

Since 2002, Ontario has moved away from market-oriented approaches to financing electricity generation investment. Earlier, the government had decided to unbundle retail energy, transmission, and generation into separate agencies that exist today. But soon afterwards, in 2002, it capped the price of electricity in the wholesale market. A central component of the market price is now the Hourly Ontario Energy Price (HOEP), which resembles the spot market price in other deregulated energy markets in North America.

However, the HOEP governs a small part of the prices that customers pay. While the HOEP is the price that determines the order in which the IESO dispatches generators, ${ }^{1}$ the Global Adjustment (GA) is now the largest part of the prices that customers are billed. The GA primarily represents the difference between what generators receive on the wholesale energy market, and out-of-market contracts and rates. These include rates paid to generators that have contracts with the OPA and to government-owned nuclear and hydro facilities, whose rates are established by the Ontario Energy Board (OEB). Fully 91 percent of Ontario's energy production is under contract to the OPA or is OEB rate-regulated (Goulding 2013b). The spot energy price on its own, however, is less than needed to stimulate investment in new generation capacity.

The Ontario government created the OPA in 2004. Under ministerial directives, the OPA centrally procures new generation and signs long-term power purchase agreements (PPAs), which typically lock in prices for long for as long as 20 years. ${ }^{2}$ It has signed contracts under the Feed-In-Tariff program for renewables, as well as for natural gas and nuclear generation. Yet, ministerial directives have politicized key choices regarding the quantities, fuels, and even locations of generation. The 2011 cancellation of the gas plant proposed for Mississauga is an extreme example of such politicization. The province recently passed legislation to enable the merger of the OPA with the IESO, but the central procurement function will live on.

\section{Twenty-Year Power Purchase Agreements: Not the Only Solution to a Market Problem}

Twenty-Year Power Purchase Agreements (PPAs) are intended to address a market problem: spot prices are perceived to be too volatile to support long-term financing for construction of generation capacity that would ensure a reliable electric system. This is not a problem unique to Ontario and occurs in many deregulated power markets. Spot markets are typically subject to caps on bids and offers and other mechanisms that cap prices. These caps mitigate generators' market power. However, they also tend to prevent prices from rising to levels that would stimulate sufficient investment in new generating capacity or maintaining existing capacity. There are exceptions, of course; Alberta and Texas have relied on spot market prices to stimulate new capacity (Newell, Spees, and Hajos 2010).

1 Dispatch refers to the process by which generators' offers are selected by the system operator to supply electricity, with lowest price offers accepted first.

2 Although these contracts are typically confidential, the 20-year duration is commonly known. See, for example: Ontario Auditor-General (2013), TransCanada Corporation (2013) and Mitsui Corporation (2007). 
While Ontario chose central contracting, most deregulated US jurisdictions chose another route: the capacity market. In addition to receiving spot energy prices when they run, most generators in the Northeastern US also receive payments for agreeing to be available to run at some period in the future.

Typically, an independent system operator (ISO) establishes how much total generation capacity it needs to assure a reliable system. It then holds a capacity auction at regular intervals. The generators enter into contracts with either an ISO-administered clearinghouse or load-serving entities such as utilities that service end customers. The ISO requires utilities to have enough capacity to meet their customers demand plus a reserve amount.

The auctions are run in advance, providing a market signal for generators to build or expand capacity in advance of when it is needed. ${ }^{3}$ In the case of the PJM Interconnection in the Mid-Atlantic and Midwest US, the largest and most developed capacity market in the US, this advance period is three years. ${ }^{4}$ Some jurisdictions in Europe have implemented capacity markets where generators are paid a price determined after they are dispatched. For example, the early (pre-2001) England and Wales capacity market was more short-term in nature: every 30 minutes. However, this mechanism was vulnerable to large generators withholding capacity to exert market power (Roques 2007).

\section{A Better Solution to a Market Problem}

A capacity market similar to that in the Northeastern US would benefit Ontario. Relative to future OPA-administered, 20-year PPAs, a capacity market could better match demand for new power capacity with how much and what type of supply materializes, resulting in less excess capacity and lower prices for consumers. A capacity market can also facilitate small-scale renewable projects to the extent this is a policy priority (Carr 2011). But 20-year PPAs result in the OPA and, by extension, Ontario ratepayers retaining large degrees of risk in relation to the price and quantity of power procured (Wyman 2008).

In theory, a central procurement function can make perfect decisions about how much and what type of capacity the market needs. However, the payments that the OPA makes under PPAs typically have a large fixed component. These payments vary little with greater-than-anticipated drops in demand, cost overruns in building, or changes in technology that lower the cost of alternative generation. Over a 20 -year period, the risk of such occurrences is substantial. When a market operator has a capacity market, ratepayers in the local jurisdiction can benefit more from developments that result in lower costs; in effect, generators absorb risk for periods more than three years out.

The aftermath of the 2008-09 recession shows the importance of risk allocation in capacity markets, and the potential benefits for consumers. In recent years, the cost of electricity in Ontario has been higher than the cost of a generic natural gas-fired combined cycle gas turbine (CCGT). In contrast, many US capacity markets saw costs at or below the cost of generic CCGT in the PJM Interconnection (Brattle Group 2011). ${ }^{5}$

3 Although three years may not be enough to incentivize nuclear, capacity markets have in general had success in providing advance incentives for natural gas generation.

4 PJM originally stood for "Pennsylvania, Jersey, Maryland," but it now includes all or parts of 13 states.

5 Customers may also hedge their purchases (or generators hedge the risks described, through contracting mechanisms). 


\section{Figure 1: PJM Capacity Market Prices}

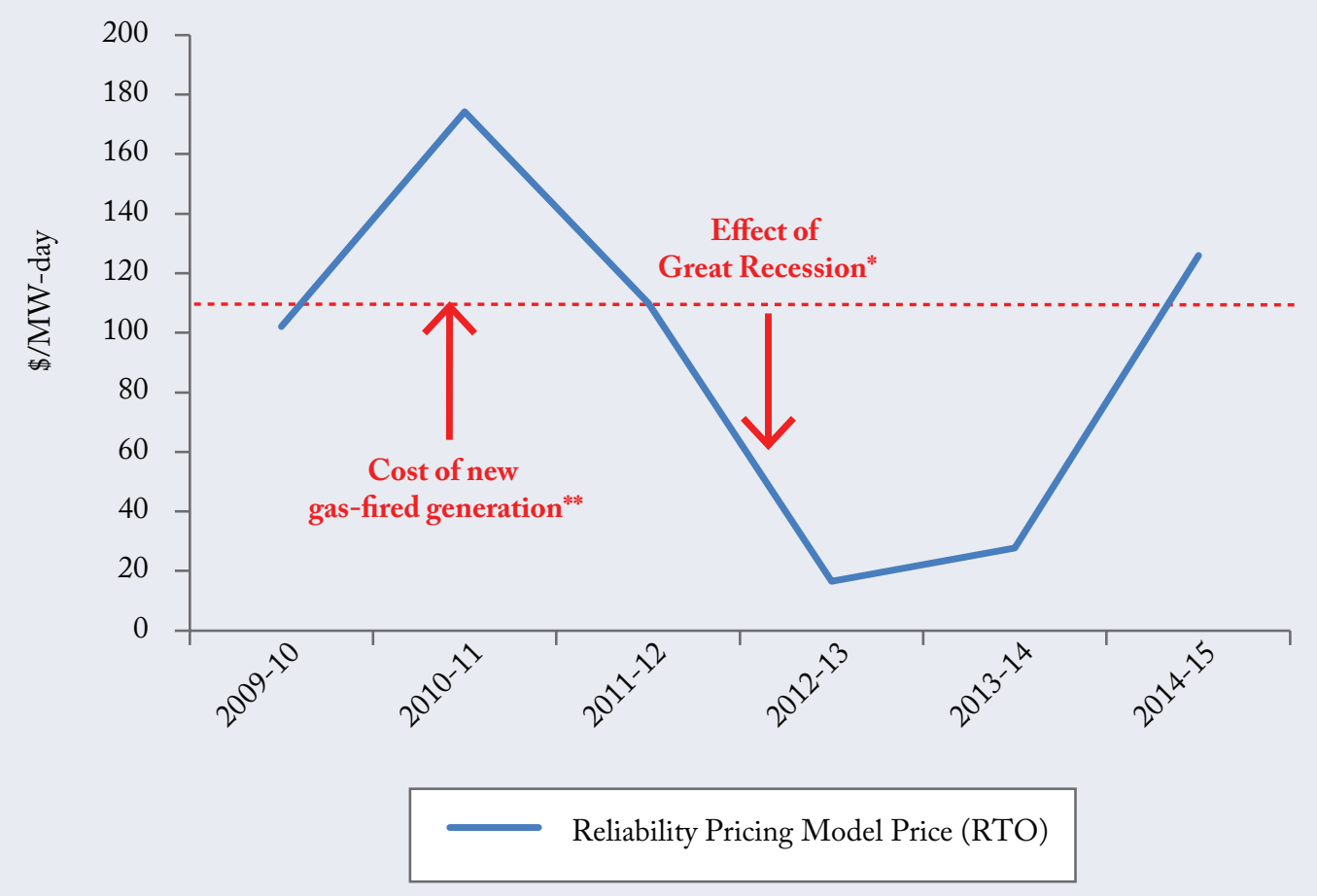

Notes:

PJM originally stood for “Pennsylvania, Jersey, Maryland," but it now includes all or parts of the 13 states.

The reliability pricing model is PJM's capacity market. It reflects the base residual auction (the principal capacity market auction), "annual" products.

*Auctions are held 3 years in advance, such that the onset of the recession (and expectations for one) in 2008-2009 were reflected primarily in the 2012-2014 delivery years.

** Long run cost of generic combined cycle-natural gas turbine.

Source: PJM 2013 Quarterly State of the Market Report.

Ontario power prices have risen since 2008 at a faster clip than in neighboring western New York State, even though both areas have seen similar input natural gas prices and tapering demand in response to economic circumstances. The increase in prices was due to a rise in Ontario's Global Adjustment (GA), with the majority of the latter due to the cost of contracts the OPA entered into for natural gas and nuclear generation capacity (Ontario Power Authority 2012).

After 2008-09, forward US capacity prices dropped, providing customers with some relief in the electricity supply portions of their bills. The drop in prices in the PJM Interconnection in the 2012 and 2013 delivery years reflects the change in market dynamics of the recession, as the auctions are held three years ahead (Figure 1). The lack of a capacity market in Ontario meant that such a decrease in costs was not possible.

A capacity market provides responsiveness to lower demand that a 20-year PPA cannot. Such 20-year PPAs ensure lower costs to consumers in the event that demand takes an unanticipated rise. However, many market observers believe that in an era of technological advances and the move to a service-based economy, the risk 
of downward pressure on electricity demand is greater than the risk of upward pressure (Kind 2013). Market participants are better placed to judge the risks associated with demand changes than a government body. A capacity market rewards or penalizes investors who hold views contrary to the majority. A 20-year PPA stifles such a process.

\section{Efficiency Benefits}

A capacity market would also provide a more economical mix of fuels and supply than centralized procurement. Currently, Ontario determines the mix of fuels (such as gas versus coal, nuclear, and renewable power) through centralized processes. That includes the Long-Term Energy Plan set by the Ministry of Energy and political level decision-making. The OPA implements the fuel mix via centralized procurement contracts.

In contrast, in a capacity market, the overall fuel mix is determined by market-based mechanisms. These, however, can be supplemented by any government-established environmental regulations and emission controls. The mix of generation that prevails in capacity market auctions then meets policy goals in an economically efficient manner, and the particular mix is a result.

Market-based mechanisms such as capacity markets therefore do a better job than central procurement at identifying the optimal fuel mix. Although many jurisdictions with capacity markets also have renewable portfolio standards and environmental regulations, these act as inputs into the decisions that market participants take. Given a certain desired level of renewable generation or emissions curtailments, the market chooses the most efficient way to retire or add generation capacity.

The market reaction to recent US EPA regulations of coal plants is an example. The PJM capacity market, home to a large amount of coal capacity, has seen widespread coal generation retirements. Instead of the EPA directing that coal plants retire, the combination of regulation and capacity markets resulted in market participants retiring over $25 \mathrm{GW}$ of coal capacity (Pfeiffenburger 2013). Ontario has already phased out its coal plants. However, any future environmental regulation could allow market participants to select the order and quantity of generation to be retired, rather than politicians.

In Ontario, a capacity market could also help avoid the issue of under-utilization of CCGT capacity relative to other fuel sources. Relative to the Northeastern US, Ontario has seen a substantial underutilization of CCGT in recent years. Ontario's combined cycle gas capacity factors averaged 26 percent in 2012 . This compares to over 50 percent for the first half of 2012 in PJM, for example (Goulding 2013b, Sotkiewiecz 2013). Again, this reflects Ontario's choice to rely on renewables and nuclear to a greater extent than regions in the United States. A capacity market would make the costs of doing so more explicit and may lead policymakers and the public to re-think costly fuel subsidies.

In addition, a capacity market could help incorporate demand-respond resources. Demand response is the ability of end-use customers to reduce their power usage in response to power-grid needs and economic signals. Those most often occur during hot days in the summer or cold days in the winter. A capacity market administrator could consider demand response as a substitute for building or maintaining generation capacity.

Demand response involves third-party aggregator companies that approach customers and arrange to remotely control their consumption, by special devices placed on lighting and air conditioning controls. These aggregators offer the customers incentives to agree to decrease their usage when given some signal by the aggregator or the system operator. The aggregator obtains revenue by bundling together multiple end-use customers and offers their bundled demand response, together as a package, into a capacity market. Many 
aggregators target commercial and industrial customers that have control over individually small but collectively large amounts of consumption.

The government's Long-Term Energy Plan hinted at this benefit when it mentioned that a capacity market would allow "different generation and demand resources to compete to address capacity needs." Indeed, allowing demand response as a capacity resource has been central to stimulating third-party aggregators and the quantity of demand response in a number of regions, including PJM.

\section{More Transparency}

To rely on a capacity market, rather than long-term PPAs, would likely lead to less closed-door decision-making and more transparency while incentivizing generation investment generally. Presently, the individual pricing associated with individual OPA contracts with natural gas counter-parties is confidential. Negotiations about extending nuclear have often taken place behind closed doors. A capacity market would force more pricing and discussions into the public domain.

\section{Avoiding One III of Politicization}

Finally, a capacity market would help allocate project development risk to the most logical risk bearer: the generation developer. In a capacity market, the promise of capacity-contract revenue in the future (in addition to energy market revenues from delivering power) creates incentives for private entrepreneurs to develop powerplant projects. The project developers bear key risks in relation to such projects. They include the risks of capital cost over-runs, which can be significant for nuclear-related projects, for example. They also take on the risk that they do not succeed in gaining required permits.

By contrast, the OPA contracts have allocated substantial project-development risk to the buyer. For example, Ontario ratepayers must cover the over $\$ 900$ million in charges in relation to relocating the Oakville and Mississauga OPA-gas contracts (Ontario Auditor General 2013). In these cases, the government revised regulations and took other steps to prevent the developers from gaining permits or building the plants, in response to environmental and/or local concerns.

If such events had taken place for a generation project in the PJM or New York markets, the project developer would have had to bear the consequences. The developer would have had sole responsibility for obtaining necessary local approval and permits. The developer would absorb the losses associated with not being able to build the plant if it failed to obtain them, even though it had sold capacity into capacity markets.

To be sure, the developer will pass through some of this risk to consumers via the energy and capacity price offers he makes. For many reasons, however, the project developer is a superior risk bearer than the government counterparty in such situations.

First, the project developer is closer to the situation on the ground and attendant risks, having gone through the legal and environmental due diligence associated with its sites. Second, the provincial government may be subject to political ramifications if it supports a controversial generation project. The market operator can design the capacity market to include requirements that generators have concluded certain environmental and municipal due diligence and permit acquisition before participating as an eligible resource. While private companies that develop generation facilities also place importance on relationships with municipalities, their interposition may help insulate economic decision-making from political winds. 


\section{A Journey that will be Worth the Trip}

How might policymakers bring about a capacity market in Ontario? The biggest existing constraint lies in Ontario's contracts for natural gas generation. While other forms of generation also participate in a capacity market, pricing in capacity markets is typically set by natural gas capacity. These units are often the marginal supplier, because they are both dispatchable and cost little to build.

The OPA has locked in gas generation capacity in contracts related to recent generation expansion or under contracts with generators known as Non-Utility Generators (NUGs). The existence of these contracts means that a lesser volume of gas capacity would be available to provide meaningful marginal price-setting than in developed capacity-market auctions in the Northeastern US. Of course, new gas capacity providers could participate in a future Ontario capacity market. But Ontario needs little new generation capacity until at least the end of the current decade (North American Electric Reliability Corporation 2013).

This timing bolsters the case for a capacity market in Ontario for two reasons. First, announcing the government's intent to implement a capacity market would set the stage for planning the end of central procurement via a phased-in implementation. Central procurement will need to continue for quite some time. It will need to continue to administer the existing long-term contracts. But central procurement was not intended to be a permanent fixture of the Ontario power market. A capacity market would be one component of ending it. Building the case with generators for a capacity market is unlikely to be an instantaneous process. Announcing the commitment to a capacity market ahead of time would give time to build credibility

Second, there will be opportunities to harmonize existing OPA contracts and the NUG contracts that come up for renegotiation. Various stakeholders in the IESO's existing process have noted that certain OPA contracts might be re-opened or affected by the implementation of a capacity market, although the exact mechanisms still remain subject to discussion and will vary by the contract in question.

A capacity market in Ontario should have features that have proven critical to the success of such markets in other jurisdictions.

- It should vary the capacity price among different geographic locations within the province, given that power demand and supply characteristics vary across a large land mass. This variance in pricing should be an outcome of the capacity market process, with geographic zones based on transmission constraints.

- The capacity market should also incorporate demand response.

- Also, it should have a defined forward obligation, with stakeholder consultation on how far forward the market should operate.

- It should set resource requirements in a well-reasoned and de-politicized way.

- It should integrate with neighboring markets, such as New York or Quebec, to the extent possible, by treating out-of-province supply as equivalent to in-province generation, to optimize the amount of exchange via interties.

- The market should avoid local-content requirements.

- The province could combine a capacity market with market-based renewable energy markets or emissions pricing.

If Ontario introduces a capacity market, politicians must commit to its longevity and effectiveness. This means avoiding discrimination between new and existing capacity resources. They must also not favor subsidies for generation that dampen market prices. 
The New Jersey and Maryland state governments in PJM, for example, attempted such subsidies after the 2009 recession. These states entered into special contracts with some generators that topped up the capacity payments that they received, with the intent of lowering the prices charged to ratepayers. These politically guided moves came at the expense of other existing generators. The US federal electricity regulator took steps which effectively weakened these subsidies, but the subsidies temporarily distorted prices in the capacity market and reduced investors' interest in building in these states. The lesson for Ontario: avoid one-off deals for politically chosen new entrants outside of the general market.

\section{Conclusion}

A capacity market could help Ontario alleviate the ills of politicization when it comes to fuel-mix and wholesalegeneration market decisions. It would lead to better risk allocation and lower wholesale power costs for Ontario consumers. To be sure, ratepayers would not feel the benefits for some years until requirements for new capacity, likely natural gas, begin in earnest. It will take political staying power and commitment. Laying the groundwork for the eventual transition from the central procurement function towards market-oriented mechanisms is a necessary first step to a reliable, efficient, electricity generation system that reduces taxpayer and ratepayer risk. 


\section{References}

Brattle Group. 2011. Cost of New Entry Estimates for Combustion Turbine and Combined-Cycle Plants in PJM. PJM.

Carr,Jan. 2011. "There's a Baby in the Bathwater." Commentary. Kitchener: Council for Clean and Reliability Electricity.

Goulding, A.J. 2013a. "Blueprints for Ontario Power Market Evolution." Presentation at Connections Symposium. December.

.2013b. A New Blueprint for Ontario's Electricity System. Commentary 389. Toronto: C.D. Howe Institute. September.

Kind, Peter. 2013. "Disruptive Challenges: Financial Implications and Strategic Responses to a Changing Retail Electric Business.” Edison Electric Institute. Washington D.C. January.

North American Electric Reliability Corporation. 2013. “2013 Long-Term Reliability Assessment.” December.

Ontario Auditor General. 2013. "Oakville Power Plant Cancellation Costs.”

Ontario Power Authority. 2012. "Current and Future Components of the Global Adjustment." Presentation to Ryerson University. Toronto: Ontario Power Authority.

Oren, S. 2000. "Capacity Payments and Supply Adequacy in Competitive Electricity Markets." VII Symposium of Specialists in Electric Operational and Expansion Planning, Curitiba, Brazil. May.

Pfeiffenburger, J. 2014. “Market-Based Approaches to Resource Adequacy.” Presentation to IESO Stakeholder Summit. Toronto. February.

Mitsui \& Co. 2007. "Project Finance for the Greenfield Energy Center.” Mitsui Corp. Press Release.

Newell, Sam, Kathleen Spees, and Attila Hajos. 2010. "Midwest ISO's Resource Adequacy Construct: A Review of Market Design Elements.” Brattle Group.

Roques, F. 2007. "Market Design for Generation Adequacy." Cambridge Working Papers in Economic, Electric Power Research Group.

Sotkiewiecz, Paul. 2013. "International Experience in Transmission Planning." PJM. January.

TransCanada Corporation. 2013. "Management Discussion \& Analysis.”Annual Report, Page 53.

Wyman, M. 2008. Power Failure: Addressing the Causes of Underinvestment, Inefficiency and Governance Problems in Ontario's Power Sector. Commentary 261. Toronto: C.D. Howe Institute. May.

\section{This E-Brief is a publication of the C.D. Howe Institute.}

Michael Wyman is a New York-based electric utility industry expert. Formerly Business Development and M\&A Manager for the largest utility in New Jersey, he is CEO of ClearGrid Innovations, a startup that helps utilities improve system efficiency and resilience.

This E-Brief is available at www.cdhowe.org.

Permission is granted to reprint this text if the content is not altered and proper attribution is provided. 